\title{
Advancing edible insects as food and feed in a circular economy
}

\author{
A. van Huis ${ }^{1^{*}}$, B.A. Rumpold ${ }^{2}$, H.J. van der Fels-Kler $x^{3}$ and J.K. Tomberlin ${ }^{4}$ \\ ${ }^{1}$ Laboratory of Entomology, Wageningen University E Research, P.O. Box 16, 6700 AA, Wageningen, the Netherlands; \\ ${ }^{2}$ Department of Education for Sustainable Nutrition and Food Science, Technische Universität Berlin, Marchstr. 23, 10587 \\ Berlin, Germany; ${ }^{3}$ Wageningen Food Safety Research, Akkermaalsbos 2, 6708 WB, Wageningen, the Netherlands; ${ }^{4}$ Department \\ of Entomology, Texas A\&M University, College Station, TX 77843-2475, USA; editor-in-chief@insectsasfoodandfeed.com
}

Received: 10 May 2021 / Accepted: 27 May 2021

(c) 2021 Wageningen Academic Publishers

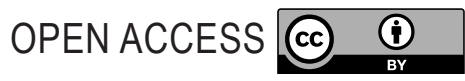

REVIEW ARTICLE

\begin{abstract}
An overview is given of the special issue on edible insects covering a number of aspects along the value change. The articles presented cover topics about producing insects both as food for humans and feed for animals, ranging from environmental impact, facility design, (left-over) substrates, the role of microbes, genetics, diseases, nutrition, to insect welfare. Possible health benefits of insects for humans and animals are discussed as well as the potential dangers in terms of allergies and chemical/biological contaminants. Regulatory frameworks are examined and assessed for remaining obstacles. The technologies dealing with the processing and extraction of proteins, lipids, and chitin were also reviewed. Consumers' perception of insect-derived food products is discussed as well. A unique aspect of this special issue within the 'Journal of Insects as Food and Feed' is a first attempt to discuss the economics of the industry. The special issue concludes with a discussion of policy and challenges facing the sector.
\end{abstract}

Keywords: edible insects, environment, nutrition, food safety, consumer attitudes, processing

\section{Introduction}

According to the International Platform of Insects as Food and Feed (IPIFF), 1 billion US\$ has been invested in the European insect industry with exciting results. For example, in 2019, its members produced more than 6,000 tonnes of insect protein (https://ipiff.org/; accessed 11 June 2021). In December 2020, Meticulous Research (2021) expect the value of the edible insects market worldwide to increase at a compound annual growth rate of $26.5 \%$ from 2020 to 2027 to reach US $\$ 4.63$ billion by 2027. In 2019, Barclays (2021) estimated the insect protein market would be worth up to US $\$ 8$ billion by 2030. In conjunction with the increased value, the number of estimated insect producers in the world now stands at 325 (BugBurger, 2021).

The academic interest is also very much recognised. A search of the phrase 'edible insects' in Web of Science (accessed 11 June 2021) resulted in 48 hits from 1945 to 2010, and 805 hits from 2011 to 2020 with more than half in 2019 and 2020 alone. The sector is diversifying, which is evidenced by the number of pet food companies that are now developing insect-based products. In fact, the first product (dried powder of yellow mealworm, Tenebrio molitor) was allowed to be marketed by the European Union (EU) in early 2021, with more products of edible insect species anticipated in the near future. This expansion and diversification may snowball, resulting in other companies becoming involved in the industry.

The articles in this special issue cover a large range of topics related to the production chain of insects as food and feed. Currently there are three types of insect farms: (1) farms purchasing eggs or small larvae from a supplier and rearing them to the harvestable stage; (2) farms covering the entire production process, from eggs to dried insects; and (3) farms that cover both production and processing (fractionating the larvae into protein, fat, and chitin) (Niyonsaba et al., 2021). As the sector develops, parts of the value chain are expected to be dealt with by separate companies. Along the chain, research and innovation will be key drivers in accelerating the transition to sustainable, healthy, and inclusive food systems from primary production to consumption (Riccaboni et al., 2021). 


\section{Insect production and facility design}

Robert Kok provides four articles reviewing preliminary project design, explained as:

the initial stage in project development that makes it possible for an entopreneur to gain insight into the feasibility and potential profitability of setting up an insect production facility.

Preliminary project design is presented as a central activity linking early concept development, data acquisition and concept crystallisation to formal engineering design, construction, and ultimate plant operation. The first article in this issue (Kok, 2021a) deals with overall mass and energy/heat balances of a rudimentary larval rearing setup. A model is proposed to make it easy for the entrepreneur to use a trial-and-error approach to investigate the effect of different parameter values on system operation. Thus, they can enter values for parameters such as feed composition, temperature of the cooling air, etc. and instantly see the effect on system productivity, conversion efficiency, energy requirements, etc. (in the supplementary material there is a spreadsheet where the reader can change the parameters). This approach facilitates the overall procedure of reaching final decisions about the organism, the feed, the processing approach, the scale of operation, etc. The entopreneur can consider various alternatives prior to making major commitment decisions. His second article in this issue (Kok, 2021b) examines the system dynamics as related to overall heat and mass balances. As demonstrated, a modelling and simulation approach based on research data allows for the integration of knowledge about organism kinetics, reactor configuration, process performance and control system activity. This may lead to a greater accuracy and precision with regards to production. Such data provides for greater understanding of all quantitative aspects of the project and the selected process type, including heat and mass flows, kinetics, inputs and outputs, dynamics, equipment requirements, etc. It should be noted in a prior publication by Kok (2017) in the book by Van Huis and Tomberlin (2017) that there are a number of basic process types already in use for industrial insect production. These topics are updated in the third article in this issue (Kok, 2021c). Sub-processes suitable for rearing insect larvae on dry and semi-dry feeds are reviewed, as well as the type of larval rearing to be employed, the reactor configuration and the operational approach to be used. Furthermore, several sub-process types, reactors, and much more are discussed. By accounting for these factors, the entopreneur should have an idea of the scope and scale of the project being proposed. In the fourth article in this issue by Kok (2021d), the project as a whole should be taken into account such as: project location issues, to what degree the facility is to be integrated or segregated into different units, what functionality is to be housed within the various building envelopes, and how safety and hygiene concerns should be addressed.

\section{Environmental impact}

Insects as food and feed have many environmental advantages. This recognition is in part due to lower greenhouse gas and ammonia emissions, reduced water and land requirements, and the ability to convert organic side streams into high-value products. To evaluate the environmental impact of insect production, both direct and indirect impacts need to be considered. This accountability can be done using a life cycle assessment (LCA). In this issue, Smetana et al. (2021) compared 24 LCA studies to determine the sustainability of insect production chains; most dealt with the black soldier fly Hermetia illucens, yellow mealworm T. molitor and house fly Musca domestica. The majority of the 24 studies assessed used the attributional LCA approach, which only takes a specific product life cycle into account; a few conducted a consequential LCA, which also considers alternative uses of a product (e.g. using manure as biogas). Most focused on cradle-to-gate approaches, not taking transportation and distribution of insect biomass/products into account. Most impacts are associated with use of energy (e.g. electricity, fuel, natural gas) and consequently global warming potential, non-renewable energy use, as well as water and land use. Type of feed and modelling of its assessment was in many cases decisive for the determination of the environmental impact of insects. Selection of by-product allocation rules, substitution criteria and waste scenarios determined the wide range of environmental impacts presented for food processing by-products, food waste and manure.

\section{Insect welfare}

Animal welfare is a critical issue for the insects as food and feed sector (Van Huis, 2021). The central question in this debate is whether insects are 'sentient beings' This may be the case when considering: (1) the very efficient functional way in which their brains are organised; and (2) their capacity for social and associative learning, and diverse ways of communication. When insects are farmed and killed, the precautionary principle is used, which assumes that they can experience pain. Van Huis (2021) used the following five freedoms of Brambell (1965) as a framework to discuss the consequences of welfare issues for the edible insect sector: freedom from hunger and thirst, from discomfort, from pain, injury or disease, from fear and distress, and freedom to express normal behaviour.

\section{Organic side streams as feed}

The kind of material (i.e. feed) that is received by an insect mass-rearing facility dictates what is produced (i.e. insect biomass, frass). This statement particularly applies to the 
insects as feed sector. Organic materials utilised to mass produce insects as feed or food can be highly diverse. Consequently, output levels, quality, and in the end, value, are highly dependent on these materials. This special issue covers the rearing of insects on manure, the role of microbes, the impact of substrate on the nutritional quality of the insect and finally how the use of leftovers (insect faeces and left-over substrate) can be used as promotor or protector of plants.

\section{Rearing insects on manure}

Cammack et al. (2021) examine the potential for animal waste (i.e. faeces) to be used as substrate for a number of insects that can serve as feed, e.g. the lesser mealworm Alphitobius diaperinus, the house fly, and the black soldier fly. While this material is not currently approved for mass production in the EU, United States, or other Western nations, it holds great potential. An overview of each species is presented as well as a case study with the black soldier fly and what is known about its abilities for recycling animal waste.

\section{Role of microbes}

Zhang et al. (2021) present a complimentary aspect of this process by discussing the use of microbes to enhance organic waste recycling in a general sense, while expanding to include other insect species, such as waxworm, Plodia interpunctella, and yellow mealworm. Furthermore, they demonstrate the possibility of using insects to recycle other waste streams than those commonly used and not yet heavily considered as substrates, such as plastics.

\section{Impact of substrate}

Pinotti and Ottoboni (2021) provide a suitable conclusion for the previous two articles discussed, as they present an overview of the impact of substrate variability on the resulting quality and value generated by the insects. They also use the black soldier fly as a case study by diving into detail on many studies that have independently explored select waste streams on the production of this insect. Now, through this study, an appreciation for the relationship between nutritional variation and optimised production can be considered.

\section{Waste as fertiliser}

Of course, the insects mass produced are just one of the primary products manufactured. The other is the digested waste mixed with insect frass that remains. Chavez and Uchanski (2021) discuss these wastes resulting from such systems (e.g. black soldier fly, house fly and mealworm) and their similarities to inorganic fertilisers. However, unlike traditional inorganic fertilisers, the waste resulting from mass producing insects contains valuable additives - mainly chitin. This material, which is a key component of insect exoskeleton, could promote plant health by reducing the likelihood of disease. They also discuss the topic that not all insect waste is the same. Differences between species, but also diets provided to these insects, influence the 'character' of the waste. Therefore, the expectation that generalisations can be drawn across systems, or even within a population that experiences variations in the diet provided to them, should be tempered.

\section{Optimising rearing processes}

One the major concerns of insect-rearing companies is the possibility that colonies will be affected by pathogens, so the first article deals with pathogen (i.e. disease) management. Another issue that companies must deal with is whether they can optimise the genetic make-up of their population to enhance production, waste conversion, and nutritional values. The other question for companies is the nutritional composition of the insects (whether this can be improved; see the article of Oonincx and Finke (2021).

\section{Disease management}

Until a few years ago the knowledge on pests and diseases in insect-rearing systems was very limited. However, insect diseases in rearing facilities, from small to industrial set-ups, are feared, as they may compromise the whole enterprise. With the growing value of this market, the increased attention to this topic for preventing and curing diseases is fully justified. Although black soldier fly larvae seem resistant to infection and disease (Joosten et al., 2020), future expansions of the industry open the door to possible disease-related issues. Safe, hygienic operating procedures and continuous monitoring will be required. Also, the development of strains resistant to pathogens should be considered, such as with viruses in crickets (De Miranda et al., 2021). In this special issue Maciel-Vergara et al. (2021) review insect pathogens that are causing disease in the most common insect species reared or collected to be used as food or feed. For the prevention of diseases, they discuss biotic and abiotic factors that may potentially trigger insect diseases. They also look at how to prevent stress factors, which are critical for the development of disease outbreaks, and often more than one pathogen is involved. The complexity of multifactorial relations requires a holistic approach to understand the various aspects related to insect diseases. For natural enemies other than pathogens (e.g. predators and parasitoids) in insect rearing systems we refer to the publication of Eilenberg et al. (2017). 


\section{Insect breeding}

While diet can certainly be used to manipulate production of insects that are mass reared, Eriksson and Picard (2021) cover this topic from a different perspective by focusing on genetics. The value of deciphering the genetic makeup of mass-produced insect species has benefitted other insect-based systems (e.g. sericulture, apiculture, biological control). By understanding these other systems, guidelines, or a framework, could be developed for these 'newer' insect systems (e.g. black soldier fly, mealworm). After discussing these more traditional systems, they provide an overview of the vast toolset (i.e. old versus new methods) available for assessing a population for strengths and weaknesses. They discuss the value of such information when breeding a population in captivity while attempting to optimise its genetic makeup as a means to enhance production, waste conversion, and nutritional value.

\section{Manipulating nutritional values}

Oonincx and Finke (2021) in this issue provide details of how insects, much like other livestock, can be manipulated to a certain extent in terms of their nutritional composition. The same authors previously gave an overview of the (a) biotic factors that may influence nutrition (Finke and Oonincx, 2014). The protein content of insects can be high and very well digested with suitable amino acid profiles (methionine being the first limiting one) for both production animals and humans. Fat content and fatty acid composition vary depending on species, life stage, diet, and sex. Most minerals are present in adequate concentrations to meet nutrient requirements of animals and humans, although calcium levels may be low depending on the model used. In insects, B vitamins are adequately present, vitamin A levels low, vitamin E concentrations depend on the diet, while vitamin D content depends on UV-B radiation during insect development. Insect processing may destroy vitamins and denature proteins due to heat. Oonincx and Finke (2021) point out that the slogan 'you are what you eat' also relates to negative aspects of the process - whereby contaminates, such as heavy metals, can bioaccumulate in insects. In conclusion, diet can strongly affect the concentration of most nutrients, but has much less of an impact on amino acids and minerals.

\section{Health aspects of using edible insects on humans and animals}

Information on the possible positive effects of insects on the health of humans and of animals is becoming more readily available; however, this advancement is only in its infant stages. This may cover all aspects from immune and microbiota responses to effects on disease resistance.

\section{Human health}

Stull (2021) discusses the impact of insects on human health. While the use of insects as food might seem novel, the practice has been in existence for as long as humanity has recorded history. Stull (2021) did an extensive literature review using SCOPUS, Web of Science, and PubMed. What she uncovered was quite surprising, as not much is known about the impact of consuming insects on human health. Results generated from her search indicate that select insects can serve as a substitute for more traditional plant-based proteins and can have a positive impact on human health by: (1) providing amino acids similar to soya; (2) improving gut health; and (3) meeting micronutrient deficiencies. However, as Stull (2021) points out, research published to date has barely scratched the surface.

\section{Animal health}

As previously mentioned, the quality of substrates used to rear insects impacts the quality of the insects produced. Consequently, the value of the insect mass produced for livestock, poultry, aquaculture, and petfood sectors can vary. However, consistency, predictability, and safety are critical if the insects are to truly be established as a dependable feed stream for farmed vertebrates for the feed industry. Gasco et al. (2021) provide an extensive overview of insects as feed across a broad spectrum of animals that are mass produced, including fish and crustaceans, poultry, pigs, and even rabbits. Initial aspects of the publication provide gross level assessment of the nutritional makeup (e.g. protein, fat, amino acid composition) of select insects that are mass produced as feed. They cover aspects ranging from immune and microbiota responses to influence on disease resistance. Other studies published in this compilation provide greater details for mass produced animals.

\section{Using insects as feed}

Insects can be used to feed fish, poultry, pigs and pets. In the articles mentioned below the effects of using insect species on these animals is discussed.

\section{Fish}

Liland et al. (2021) provide an extensive evaluation of published literature examining the use of insects as feed in the aquaculture industry. This assessment evaluated 91 publications, 415 experimental diets across 35 fish species, while considering 14 insect species. Assessment of the studies indicates a high degree of breadth across these criteria demonstrating the diversity of the aquaculture industry. However, while of tremendous value simply for amassing such an extensive, and diverse literature, Liland et al. (2021) demonstrate a critical limitation. In general, the industry still appears to be lacking depth of understanding 
for a targeted fish being reared on insect-based diets as well as the value of a given insect species as a diet for the diverse global aquaculture industry.

\section{Poultry}

Dörper et al. (2021) produce a similar evaluation of insects as feed for the poultry industry. They also explored various insect models that can be used presently (e.g. black soldier fly), or possibly if approved (e.g. house fly, yellow mealworm) as a feed. Unlike the aquaculture industry, fewer data are available on the use of these insects as feed. Dörper et al. (2021) provide an overview of the benefits of insects as feed for the poultry industry ranging from improved animal health to conversion rates across the different sectors (e.g. layers, broilers). Their extensive summary table highlights studies where insects have been used as poultry feed: an overview of the associated results as well as the references.

\section{Pigs}

Similar to other domestic stock previously discussed, Veldkamp and Vernooij (2021) provide an overview of the use of insects as feed for pigs. They discuss the pig industry and its value as well as its reliance on traditional row crops for feed. This initial discussion sets the stage for their presentation of data generated from studies that examined the inclusion of insects as part of the feed used to rear pigs. They demonstrate aspects of the pig diet that can be replaced. However, they recognise variability in the results generated (i.e. pig response to being fed such diets) from such studies. They conclude by offering their support for including insects in the pig diet as they do not adversely impact associated growth; however, additional research is needed to determine if differences between studies are due to the insect diet or some other covariate.

\section{Pets}

A recent advancement in terms of regulations in various parts of the world has been the approval of insects for use in pet food. Bosch and Swanson (2021) discuss the use of such products as part of dog and cat food. The stage for their discussion is set by providing an overview of the pet food industry. They recognise each has its own parameters with regard to formulations (e.g. palate, nutrition, and indirectly - owner preference for pet food). Unlike other studies published in this special issue, they focus on the amino acids that are key drivers in the dog and cat food industries. Methionine, threonine and leucine levels are key when making decisions about which components to include in dog and cat food. They then transition into discussing what is known about insects as dog and cat food by providing extensive tables and reviewing previous studies published.

\section{Food safety and legislation}

When talking about food safety of insects as food and feed, there are a number of issues that need to be considered, such as, but not limited to: allergy, as insects are closely related to crustaceans (Pennisi, 2015), biological and chemical contaminants, and of course the legal framework.

\section{Allergy}

Ribeiro et al. (2021) reviewed 20 articles and provide an update on scientific developments related to the allergic risks of insects as food. They specifically looked at the molecular mechanisms and major allergens implied both in primary sensitisation and in cross-reactivity with crustaceans or house dust mites. They also discuss the effect of food processing on allergenicity of edible insects. Food allergies are defined as adverse immune responses to food proteins that result in typical clinical symptoms involving the dermatologic, respiratory, gastrointestinal, cardiovascular, and/or neurologic systems (Anvari et al., 2019). The most common type, which occurs shortly after eating, is immunoglobulin $\mathrm{E}$ (IgE)-mediated. When immune cells encounter the allergenic protein, IgE antibodies are produced, which initiate the allergic reaction. Ribeiro et al. (2021) concluded that: (1) tropomyosin is confirmed to be a cross-reactive allergen between edible insects and crustaceans; (2) allergenicity of edible insects seems to be resistant to thermal treatments and digestion with enzymes, and only the use of very specific conditions can eliminate the IgE-reactivity of edible insects; (3) clinical significance in cross-reactivity between edible insects and house dust mites is still unclear, in particular for subjects who are only allergic to house dust mites; (4) major risk groups are those who are involved in rearing the insects and those that are allergic to crustaceans. An effective allergen management procedure is the correct labelling of insect-containing foods (Garino et al., 2020).

\section{Biological contaminants}

Biological contaminants encompass pathogenic strains of microorganisms (i.e. bacteria, viruses and fungi), parasites (i.e. protozoa and worms), as well as toxic substances (chemicals) they produce, i.e. mycotoxins. Vandeweyer et al. (2021) review first the possible occurrence of biological contaminants (excluding toxic compounds produced) in mass-rearing systems and then discuss future challenges. Concerning wild-harvested insects, they refer to other publications. From the review they conclude that: (1) data regarding prions and foodborne viruses and parasites in insects farmed for human consumption are scarce; (2) the most important bacterial pathogens associated with insects for food are Staphylococcus aureus, pathogenic Clostridium spp. and pathogenic species of the Bacillus cereus group. The last group are spore-forming bacteria 
and drastic strategies are required to mitigate the risks associated with bacterial endospores. Concerning insects for feed, few reports on pathogens seem to be available. Prions cannot be produced by insects, but could be acquired from slaughterhouse waste (EFSA Scientific Committee, 2015). Vandeweyer et al. (2021) also made an assessment on the transfer of biological contaminants during the rearing (e.g. contamination from the diet). They also mention further challenges which we discuss in Section 12.

\section{Chemical contaminants}

Meyer et al. (2021) review the hazards of chemical contaminants and focus on substrates for twelve edible insect species. Most data are available for the black soldier fly and the yellow mealworm. Chemical contaminants investigated so far include heavy metals, dioxins and polychlorinated biphenyls, polyaromatic hydrocarbons, pesticides, veterinary drugs, mycotoxins, and plant toxins. Those chemicals are generally stable, and it is difficult to remove or reduce them by processing. Transfer and bioaccumulation depend on the insect species, life stage, substrate type, chemical involved, source (spiked vs natural), and rearing conditions. Accumulation occurs with lead, arsenic, mercury, and cadmium, but apparently not for mycotoxins and polycyclic aromatic hydrocarbons. Although mycotoxins and veterinary drugs can be degraded by insects, the metabolites formed and their possible toxicity is not clear. Few data are available for possible accumulation (or degradation) of polyaromatic hydrocarbons, plant toxins, and dioxins and dioxin-like polychlorinated biphenyls.

\section{Regulatory issues}

Lähteenmäki-Uutela et al. (2021) compare insect food and feed regulation in the EU, the United States, Canada, and Australia and to some extent in countries of Central and South America, Asia and Africa, in particular for the period from 2018 to 2020. Food and feed regulations are often separate; feed regulation may allow insect usage even when they are not allowed as food. In the EU applications for food products from seven insect species have been submitted, and the first assessment by the European Food Safety Authority was adopted on 20 November 2020 for dried powder of the yellow mealworm (EFSA, 2021). The other insects may continue to be marketed until the EU makes a decision. In 2017, the EU decided to allow the use of seven insect species as aquafeed. However, insect proteins are not allowed to be fed to pigs and poultry nor are foodstuffs containing meat or fish allowed to be used as feed materials for insects. In Canada black soldier fly products have been authorised as feed for poultry and certain fish species. In China silkworm pupae are authorised as a food ingredient. However, insects as food and feed should be regulated globally as the regulatory demands and differences between countries complicate the international marketing strategies for insect products. Insects proven safe as food and feed by the scientific community should be authorised in all countries (Lähteenmäki-Uutela et al., 2021).

\section{Processing}

Several industrial technologies are used for processing, such as grinding, separation and drying (Sindermann et al., 2021). Then in the chapter of Ojha et al. (2021).in this issue the extraction and utilisation of insect protein, lipid and chitin as well as novel processing technologies are discussed

\section{Technologies}

The adoption of insects as food and feed on an industrial level is, besides the issue of acceptance, hindered by regulatory aspects and by the challenge of up-scaling production at a competitive price. Up-scaling also concerns processing of insects into food and feed products. This aspect requires species-specific, cost-effective, and targeted technologies and machines. It is not necessary to reinvent the wheel; existing processing technologies can be adapted and optimised for the separation and/or processing of insects into intermediates and products for use in food and feed. An overview of existing industrial processing technologies for insect larvae is given by Sindermann et al. (2021). The authors distinguish between wet and dry processing, which refers to the use or lack of use of water and a drying step before or after the potential lipid removal. Several machines for grinding, separation and drying were presented. It was concluded that automation and cleaning in situ are additional aspects to be considered when designing a processing line. It was stated that the adaption and adjustment of existing technologies will meet the processing demand of an up-scaled insect production set-up in due time.

\section{Processing and extraction pathways and emerging technologies}

Insect processing is crucial to ensure safe and high-quality raw materials and food products based on edible insects. In addition to unit operations already traditionally used in food processing, emerging technologies such as high hydrostatic pressure processing, ultrasound, cold plasma or pulsed electric fields have shown potential for insect processing. In their review, Ojha et al. (2021) give an overview of traditional and future processing pathways and technologies for insect processing. This ranges from pre-processing (harvesting, cleaning, killing) through decontamination to packaging and storage. Conventional processing routes and their processing steps to produce whole insects, whole-fat meal, fermented insect meal, defatted insect meal, insect oil and other insect fractions such as protein and chitin are presented. In addition, 
potential processing pathways using emerging technologies are shown. The authors conclude that the main challenges of insect processing include the development of low-cost and sustainable processing technologies with a holistic approach concerning by-products and production waste. While emerging technologies offer a number of benefits, there are still hurdles such as a necessary high level of knowledge and the plant costs.

\section{Consumer and marketing}

Despite the nutritional and environmental benefits of insects, consumer acceptance is still low, especially in Western countries (Motoki et al., 2021). For a successful promotion of insects as food, an in-depth understanding of the consumers' perception is fundamental. Consumer attitudes regarding the acceptance of insects as food have been reviewed in a number of articles among which Hartmann and Siegrist (2017), Mancini et al. (2019), Motoki et al. (2021) and Sogari et al. (2019). The studies vastly differ in methodology and approach. A systematic analysis of these studies and pooling of their results could elucidate the consumers' perception of insects as food and highlight research gaps, something that has been done by Wassmann et al. (2021) in this issue. Consumer attitudes may also be influenced by how the products appear on the market (Reverberi, 2021). Finally, the economics of insect production has until now scarcely been addressed. A first attempt has been made by Niyonsaba et al. (2021) to shed more light on the profitability of insect farms.

\section{Consumer attitudes}

In a meta-analysis, (Wassmann et al., 2021) assessed 37 research publications with the objective of investigating the correlation between willingness to consume and several (34) variables. A small correlation was found with gender, female participants being less likely to consume insects. Strong links were found for variables related to the novelty and acceptability of insects as food as well as to affective factors such as disgust, the latter being the greatest barrier. Wassmann et al. (2021) conclude that one key to overcoming disgust is tastiness, as disgust is closely related to taste (Rozin et al., 2009). The most positive impact on the consumers' willingness to taste insects as food is awareness of the environmental benefits of such products (Wassmann et al., 2021). Moderating effects on willingness to consume were the presentation of the insect product (description, picture or real product).

\section{Economics}

Data on the profitability of commercial-scale insect production are scarce. Niyonsaba et al. (2021) made a first attempt to obtain insight into the economics of insect production. They looked at four insect species: the black soldier fly, the yellow mealworm, the house cricket Acheta domesticus, and the lesser mealworm, though few data are available for the latter. There is a huge variation in sales prices (Table 1), due to: (1) the market type (feed, pet food or human consumption; pet food often concerns small quantities); (2) large differences in operational costs (per unit of water, electricity, labour and feed) in particular among regions (costs in developing countries often being low); (3) fresh or processed larvae (processing requires extra costs); (4) differences in level of mechanisation (often related to economies of scale); (5) differences between rural and urban areas. The prices and feed costs for house cricket meal are considerably higher than those for the black soldier fly and mealworms. This may be the reason that food and feed companies consider mealworms and black soldier fly more attractive to include in their products than crickets (Niyonsaba et al., 2021). This is because price is considered an obstacle in using insect products (Brynning et al., 2020). Major operational costs are those of feed and labour, with feed costs varying substantially within and between insect species.

\section{Packaged processed food}

Even with a willingness to consume insects, most Western consumers still lack the skills to prepare insectcontaining meals at home. Ready-to-eat or ready-to-cook insect products can facilitate their use and consumption. Emerging insect products are cookies, bars, crisps, pasta, meat balls, schnitzel, pasta sauces, or even whole insects.

Table 1. Sales prices and average operational costs according to edible insect species and regions; data from Niyonsaba et al. (2021).

Range of sales prices (€/tonne)

World

$1,816-18,900$

$5,727-97,000$

$18,182-84,590$
Average operational costs (€/tonne $)^{1}$

Canada, EU and Canada

Hermetia illucens (dried)

Tenebrio molitor (fresh)

iectricily, water and gas.

${ }^{1}$ Operational costs include feed, labour, electricity, water and gas. 
Most of them contain cricket flour or mealworm larvae flour. Despite the vast media coverage, insect products have not yet succeeded in becoming mainstream; they still remain a niche product (Reverberi, 2021). For start-ups, a major challenge is the identification of target groups and selling points. Producers target LOHAS (Lifestyle of Health and Sustainability) (Pittner, 2017) consumers, foodies, flexitarians, and even vegetarians (Reverberi, 2021). Potential selling points, apart from taste, include nutritional and environmental benefits and using the claim 'superfood'. Packaging should be modern and 'mainstream' with a clear indication that the product contains insects. In addition, an allergen warning must be included on the label. Further challenges include market size estimates, supermarket outlets, and competitive prices. Co-packers are used by $80 \%$ of start-ups to facilitate manufacturing, packaging and labelling, certification, storage and shipping (Reverberi, 2021). Based on the interviews, they conclude that bias against consumption of insects, high production costs, regulatory barriers, and access to retail markets are the main challenges when marketing insect products.

\section{Challenges}

What are the challenges that lie ahead in the sector of insects as food and feed? The editors of the special issue discuss how these challenges can be tackled, using among other things the recommendations of the authors of the special issue.

\section{Exploring other insect species}

The most commonly reared insect groups - cricket, mealworm, and black soldier fly - derive protein from the substrate. This means that the limitation is the amount of protein in the feed. In the drive towards a circular economy, the substrates that contain some protein will increasingly compete with other uses. For example, Pinotti et al. (2021) showed that food leftovers (former food products and bakery by-products - also targeted by the insect industry) can be used as an alternative to traditional feed ingredients in pig and ruminant nutrition. Hence, the livestock sector is also focussing on food waste as feed, avoiding competition for natural resources, and reducing the environmental impact of the animal production systems. Organic side streams are competed for and this will make them increasingly expensive. Low-cost feeds are often those composed of cellulose and lignin and low in protein. To be able to use those as feed, can we use organisms able to digest it or able to synthesise protein? Several beetles, some cockroaches and most termites can do much of this, aided by bacteria and protozoa living symbiotically in their guts. The combination of microorganisms and insects needs full attention, e.g. some microbial symbionts of arthropod guts are able to synthesise protein de novo from atmospheric nitrogen (Douglas, 2009; Nardi et al., 2002). One possibility is also to feed the insects with fungi-fermented high cellulose and lignin substrates (Qi et al., 2019).

\section{Environmental impact and insect welfare}

Smetana et al. (2021), who compared several environmental impact studies of insects as food and feed, state that in order to achieve consistency and comparability of results, future studies should carefully determine system boundaries, scale of production, the reference (functional) unit, and the methodology used for impact assessment, e.g. what type of life cycle analysis is used (attributional or consequential).

Concerning insect welfare, an international effort should be made to establish guidelines or standards of care for the industry about well-being and slaughter (Van Huis, 2021), while also considering limitations that developing nations face. Any guidelines developed should be sensitive to diverse socio-economic standards that exist globally, and care should be taken to avoid excluding other nations that are financially disadvantaged. Also, more information is needed on the cognitive and emotional capacity of invertebrate species. The choice of species should reflect the enormous diversity in nervous structures and the quantity of the species reared.

\section{Organic side streams to rear insects}

In general terms, between 55 and $95 \%$ of the nitrogen $(\mathrm{N})$ and about $70 \%$ of the phosphorus $(\mathrm{P})$ ingested by livestock are excreted through urine or faeces (Leip et al., 2019). When not disposed of, wasted or applied in excess of crop nutrient needs, can manure be considered a co-product and used sustainably? One of the possibilities is biodegradation/ biotransformation of manure by insects, and Cammack et al. (2021) explains it as follows:

first from waste to fly larvae as feed for chickens; then the manure from the chickens can be upcycled by black soldier fly into purified proteins and amino acids for aquaculture feeds, oil for biodiesel, and the frass for soil amendment.

They pose the question whether the lesser mealworm, house fly, and other insects will also have such abilities.

The role of microbes in this process is crucial as explained by (Zhang et al., 2021). Even plastic biodegradation can be accelerated by mealworm and their gut microbiome (Brandon et al., 2021). Also, Peng et al. (2019) demonstrated that Tenebrio species and their gut microbes were able to biodegrade polystyrene.

The left-over substrates from insect mass-rearing farms can be used to promote plant growth and health, the latter probably through chitin (Chavez and Uchanski, 2021). They 
also indicated that levels of bioavailable phosphorous (P) in insect frass are high, which is important considering the limited availability of $\mathrm{P}$ for agriculture in the future.

\section{Optimising rearing processes}

Maciel-Vergara et al. (2021) made several recommendations about disease management, such as having a clear understanding of the biology of insect pathogens and the interactions with their hosts and knowing the correlation between production variables and host-pathogen dynamics. They also stress that protocols need to be developed for the management, prevention, and control of diseases.

Eriksson and Picard (2021), while discussing genetic and genomic selection, predict that next-generation molecular technologies, such as the CRISPR/Cas genome editing toolkit, will fuel future innovations. They mention approaches to isolate and characterise genetic variants linked to phenotypes. What has not yet been researched is the role of endosymbionts, such as Wolbachia, which for example could have a role in the degradation of waste. Kaya et al. (2021) are concerned that the genetically highly uniform domesticated strains of the black soldier fly threaten the genetic integrity of unique local resources through introgression.

Oonincx and Finke (2021) discuss the manipulation of the nutritional composition of insects, which can be done by: (1) harvesting a specific life stage; (2) diet composition; (3) environmental manipulation (e.g. vitamin D3 synthesis in yellow mealworm by UV-B emission; Oonincx et al. (2018)); (4) processing (mostly in a negative way, e.g. destruction of vitamins and denaturation of proteins due to heat).

\section{Health aspects of insects as food and feed}

The health benefits of insects as food and feed for people, livestock, poultry, fish, and pets has received increasing attention. If there are health benefits, it will certainly boost the interest of potential users. However, concerning those benefits for human health, Stull (2021) recommend rigorous and well-controlled human intervention trials not only to confirm health benefits but also to assess the associated risks. What also needs to be addressed are issues like nutrient bioavailability, the fate of dietary chitin, and in vivo activity of bioactive peptides.

Gasco et al. (2021) consider that insect use as animal feed is impaired by high prices and low availability. These issues are due to the lack of large-scale production units and legislation uncertainties. Insect consumption by animals seems to stimulate the immune system, improving disease resistance. This action of insects as a prebiotic in animals is of interest because antibiotic resistance is a major public health concern: between 2010 and 2030, the global consumption of antimicrobials is estimated to increase by 67\% (Van Boeckel et al., 2015); and resistant bacteria in animals could be pathogenic to humans (Manyi-Loh et al., 2018). According to Gasco et al. (2018) what still needs to be determined for each mass-produced insect species is the dose and duration of administering the insect product and which kind of diseases the product protects against in aquatic and terrestrial farmed animals.

\section{Insects as feed}

The feed market represents about 1,040 million tons, of which poultry uses $45 \%$, pigs and ruminants each another 24-25\%, and aquaculture and pets each another 3-4\% (Table 2 ). The global commercial feed manufacturing sector generates an estimated annual turnover of over US \$400 billion (IFIF, 2021).

In most countries the use of insects as aquaculture feed or for pets is allowed. If it were allowed for poultry and pigs in other parts of the world outside the United States, where it is already approved for black soldier fly, this would create an enormous market. In four articles dealing with aquafeeds, poultry, pigs and pets, the prospects of using insects as feed are examined.

Aquaculture is growing about 5\% a year and in 2018 produced 82 million tonnes, valued at USD 250 billion (FAO, 2020). Half of all global seafood production for human consumption is farmed, and this demand is expected to rise to over $60 \%$ by 2030 (CAIA/FCC, 2021). Aquafeed is about $4 \%$ of all feed produced worldwide (Table 2 ). In the development of sustainable aquafeeds, a major challenge is to lower its dependence on fish meal and fish oil. According to Liland et al. (2021) about a quarter of the feed can contain insects without reducing the performance of the aquaculture species. The limitation to using insects as aquafeed is reduced protein digestibility, imbalanced amino acid profile and increasing levels of saturated fatty

Table 2. Feed production estimates in million metric tons of feed in 2019 (Alltech, 2020).

\begin{tabular}{|c|c|c|}
\hline & Million metric tons & $\%$ \\
\hline Poultry & 465.0 & 44.7 \\
\hline Layer & 157.7 & \\
\hline Broiler & 307.3 & \\
\hline Pig & 260.9 & 25.1 \\
\hline Ruminant & 245.3 & 23.6 \\
\hline Beef & 115.4 & \\
\hline Dairy & 129.9 & \\
\hline Aquaculture & 41.0 & 3.9 \\
\hline Pet & 27.7 & 2.7 \\
\hline Total & $1,039.9$ & 100 \\
\hline
\end{tabular}


acid. Another problem is the high variation in quality and compositions of insect meals for the non-defatted meals and insect oils.

Close to a half of all the feed produced goes to poultry (Table 2). There are legislative hurdles in a number of countries regarding its use. Partial replacement of fishmeal or soybean meal by fly larvae is possible. As the animals need to forage to obtain the insect, the welfare of the animals could be enhanced. Dörper et al. (2021) recommended: (1) standardised procedures for insect production and processing; (2) distinction between insect products based on their nutritional composition; (3) determination of optimal inclusion levels for insect products per poultry species; (4) comparison of products from different insect species.

One quarter of all feed produced goes to pigs (Table 2). Veldkamp and Vernooij (2021) suggest that in order to understand the effects of the insect products in diets a distinction should be made between studies to determine nutritional value (digestibility studies) and growth performance. They also recommend more standardised digestibility and growth performance experiments. The potential effects of the use of insect-based ingredients on animal health are interesting and deserve more attention.

Although only $3 \%$ of the feed produced goes to pets (Table 2), in 2020 and 2021 an increasing number of pet feed companies marketed insect-based feed products. The insect-containing hypoallergenic foods are now an option for owners with dogs or cats suffering from supposed or diagnosed food sensitivity. Bosch and Swanson (2021) recommend for insect-based ingredients in pet food: (1) safety and efficacy testing; (2) a study of the impact of long-term feeding on the nutritional status and health in dogs and cats; (3) an exploration of the health benefits of insect ingredients in feed on pets; (4) a survey of consumer attitudes specifically when the insects are grown on organic side streams.

\section{Food safety and legislation}

Vandeweyer et al. (2021) consider the following as major challenges for mitigating the risk of biological contaminants:

(1) risk assessments directed at specific insect species;

(2) more data required on the microbiological quality of substrates and residue and in relation to this the development of decontamination treatments; (3) investigating the house flora of rearing facilities; (4) implementing exhaustive sampling plans by applying predictive microbiology; (5) standardisation of microbiological research methods and quality control; (6) exploring the unculturable fraction of the insect microbial community and its importance in food safety; (7) developing monitoring and control protocols of biological contaminants in the upscaling of the sector. Concerning the chemical contaminants
Meyer et al. (2021) recommend further research on the metabolic pathways of mycotoxins and veterinary drugs in insects, as detoxification/bioactivation pathways are not clear. The growth of the insect sector is constrained by a lack of (1) local regulations, and (2) a stable and consistent set of regulations across international borders (Lähteenmäki-Uutela et al., 2021). A future perspective given by Lähteenmäki-Uutela et al. (2021) is that if the familiar insect species are eventually authorised in all major countries, and the authorisations are generic, researchers and companies may shift their attention to new species.

\section{Processing}

For some of the technologies discussed, economies of scale require larger production volumes than most systems in operation today (Sindermann et al., 2021). Even though the insect industry will probably come up with many new product innovations within the near future, the major technologies for dry and wet processing are ready to be applied. In upscaling, some equipment may require minor adjustments.

The main challenges of insect processing include developing efficient, sustainable, and low-cost processing technologies, waste minimisation, recovery, and incorporation of byproducts/co-products (Ojha et al., 2021). Novel foodprocessing technologies should improve the processing efficiency, safety, quality, and sustainability of insect-based products, although the know-how required and the high costs are still hurdles.

\section{Consumer attitudes and marketing}

Wassmann et al. (2021) feel that classical psychological factors have been sufficiently researched and suggest that future studies on willingness to consume should be more market-oriented, focussing on marketing and product development, and on variables like price, convenience, species, and packaging. However, there is a psychological factor that may need to be further explored, i.e. Youssef and Spence (2021) proposed a multisensory environment for a gastronomic dining experience, e.g. when having an insect dish, incorporate natural sounds (singing crickets), project nature videos, and provide ambient aromas.

Insect products are not yet mainstream, although they have been on the market for about 10 years. According to Reverberi (2021) the commercial challenges include lowering production costs, facilitating certifications and regulations, improving marketing, increasing retail distribution and expanding consumer targeting.

In the study by Niyonsaba et al. (2021) on the profitability of insect farms, there was a wide variety of sales prices and operational costs. They recommend: (1) research on the 
effect of scaling-up on profitability; (2) more knowledge about farm outlet prices to calculate a reliable gross margin; (3) inclusion of capital expenditures and financing costs in the calculation of profitability; (4) obtaining an overview of prices and costs per geographical location to identify which production systems are most appropriate for which country (e.g. in terms of the amount of labour needed).

\section{Conclusions and policy}

The IPIFF with 76 members in 2021 (https://ipiff.org/; accessed 11 June 2021) has been productive and impactful. With its secretariat in Brussels, the organisation can represent the interests of the insect production sector to EU policy makers, European stakeholders, and citizens. Their publications are high standard and cover a range of topics such as hygiene, sustainability, and the use of insect frass, etc. On other continents there are also stakeholder organisations such as the North American Coalition of Insect Agriculture (NACIA). Its role is to encourage the positive use of insects in North America, and educate and help build awareness and acceptance for insects as a solution to up-cycle nutrients back into the food chain. In Australia in 2021 a roadmap was published as a strategy to advance the edible insect industry (Ponce-Reyes and Lessard, 2021). In this country there is the Insect Protein Association Australia (IPAA) promoting the use and role of insects within the Australian food and feed ecosystem to government, academia, and industry. In Asia, there is the Asian Food and Feed Insect Association (AFFIA) representing the interests of its members from the industry and from academia working with insects as food and feed in Asia; China, however, is not included. In Africa there is the African Association of Insect Scientists (AAIS), however their mandate is much broader than edible insects. It may be time to coordinate efforts at a global level.

The reason for the creation of IPIFF was the lack of a regulatory framework for edible insects, which was considered a major hurdle in advancing the industry. With the expected easing of the legislation for insects as food and feed, it is anticipated that the sector will develop quickly. With a conducive regulatory framework, companies will no longer face uncertainties and academics will no longer be restricted by legislation. In fact, they can be a major contributor to the easing of legislation. For example, Belghit et al. (2021) proposed a molecular method for improved detection, differentiation and tracing of prohibited material in processed animal proteins (PAPs) derived from insects in feed chains. This may contribute to lifting the feed ban rules as the transmissible spongiform encephalopathy regulation in the EU prohibits the use of PAPs derived from insect in feed for pigs and poultry.

Research in insects as food and feed can initiate new developments such as: genetically improving breeding stocks; promoting health for humans, animals, and plants; safe use of substrates such as manure or catering waste; reducing environmental impact by lowering emissions of greenhouse gases, ammonia, and nitrogen; biotransforming waste; creating new insect products, for example, for cosmetics; and many more developments can be added in the production, processing and consumption of edible insects.

Maybe it is also time for an academic society through which researchers from all over the globe could communicate on edible insect issues. There are exciting times ahead for all of us, rich with opportunities to use insects for our benefit.

\section{Conflict of interest}

The authors declare no conflict of interest.

\section{References}

Alltech, 2020. 2020 global feed survey. Alltech, Nicholasville, KY, USA. Available at: https://www.alltech.com/sites/default/files/ GFS_Brochure_2020.pdf.

Anvari, S., Miller, J., Yeh, C. and Davis, C., 2019. IgE-mediated food allergy. Clinical Reviews in Allergy \& Immunology 57: 244-260. https://doi.org/10.1007/s12016-018-8710-3

Barclays, 2021. Insect protein: bitten by the bug. Barclays, London, UK. Available at: https://www.investmentbank.barclays.com/ourinsights/insect-protein-bitten-by-the-bug.html

Belghit, I., Varunjikar, M., Lecrenier, M.C., Steinhilber, A.E., Niedzwiecka, A., Wang, Y.V., Dieu, M., Azzollini, D., Lie, K., Lock, E.J., Berntssen, M.H.G., Renard, P., Zagon, J., Fumière, O., Van Loon, J.J.A., Larsen, T., Poetz, O., Braeuning, A., Palmblad, M. and Rasinger, J.D., 2021. Future feed control - tracing banned bovine material in insect meal. Food Control 128: 108183. https://doi. org/10.1016/j.foodcont.2021.108183

Bosch, G. and Swanson, K.S., 2021. Effect of using insects as feed on animals: pet dogs and cats. Journal of Insects as Food and Feed 7: 795-805. https://doi.org/10.3920/JIFF2020.0084

Brambell, F.W.R., 1965. Report of the Technical Committee to enquire into the welfare of animals kept under intensive livestock husbandry systems. Cmnd. 2836, December 3, 1965. Her Majesty's Stationery Office, London, UK.

Brandon, A.M., Garcia, A.M., Khlystov, N.A., Wu, W.-M. and Criddle, C.S., 2021. Enhanced bioavailability and microbial biodegradation of polystyrene in an enrichment derived from the gut microbiome of Tenebrio molitor (mealworm Larvae). Environmental Science \& Technology 55: 2027-2036. https://doi.org/10.1021/acs.est.0c04952 Brynning, G., Bækgaard, J.U. and Heckmann, L.-H.L., 2020. Investigation of consumer acceptance of foods containing insects and development of non-snack insect-based foods. Industrial Biotechnology 16: 26-32. https://doi.org/10.1089/ind.2019.0028

BugBurger, 2021. The eating insects startups: here is the list of entopreneurs around the world! Available at: http://www. bugburger.se/foretag/the-eating-insects-startups-here-is-the-listof-entopreneurs-around-the-world 
Canadian Aquaculture Industry Alliance \& Fisheries Council of Canada (CAIA/FCC), 2021. Canada's blue economy strategy 2040. CAIA/ FCC, Ottawa, ON, USA. Available at: http://fisheriescouncil.com/ wp-content/uploads/2020/10/Canadas-Blue-Economy-Strategy_ FINAL-9-15-2020.pdf

Cammack, J.A., Miranda, C.D., Jordan, H.R. and Tomberlin, J.K., 2021. Upcycling of manure with insects: current and future prospects. Journal of Insects as Food and Feed 7: 605-619 https:// doi.org/10.3920/JIFF2020.0093

Chavez, M. and Uchanski, M., 2021. Insect left-over substrate as plant fertiliser. Journal of Insects as Food and Feed 7: 683-694. https:// doi.org/10.3920/JIFF2020.0063

De Miranda, J.R., Granberg, F., Onorati, P., Jansson, A. and Berggren, Å., 2021. Virus prospecting in crickets - discovery and strain divergence of a novel iflavirus in wild and cultivated Acheta domesticus. Viruses 13: 364. https://doi.org/10.3390/v13030364

Dörper, A., Veldkamp, T. and Dicke, M., 2021. Use of black soldier fly and house fly in feed to promote sustainable poultry production. Journal of Insects as Food and Feed 7: 761-780. https://doi. org/10.3920/JIFF2020.0064

Douglas, A.E., 2009. The microbial dimension in insect nutritional ecology. Functional Ecology 23: 38-47. https://doi.org/10.1111/ j.1365-2435.2008.01442.x

European Food Safety Authority (EFSA), 2021. Safety of dried yellow mealworm (Tenebrio molitor larva) as a novel food pursuant to Regulation (EU) 2015/2283. EFSA Journal 19(1): 6343. https://doi. org/10.2903/j.efsa.2021.6343

European Food Safety Authority (EFSA) Scientific Committee, 2015. Risk profile related to production and consumption of insects as food and feed. EFSA Journal 13: 4257. https://doi.org/10.2903/j. efsa.2015.4257

Eilenberg, J., Gasque, S.N. and Ros, V.I.D., 2017. Natural enemies in insect production systems. In: Van Huis, A. and Tomberlin, J.K. (eds.) Insects as food and feed: from production to consumption. Wageningen Academic Publishers, Wageningen, the Netherlands, pp. 201-223. https://doi.org/10.3920/978-90-8686-849-0

Eriksson, T. and Picard, C.J., 2021. Genetic and genomic selection in insects as food and feed. Journal of Insects as Food and Feed 7: 661-682. https://doi.org/10.3920/JIFF2020.0097

Food and Agriculture Organisation (FAO), 2020. The state of world fisheries and aquaculture 2020 - sustainability in action. FAO, Rome, Italy. https://doi.org/10.4060/ca9229en

Finke, M.D. and Oonincx, D., 2014. Insects as food for insectivores. In: Morales-Ramos, J.A., Guadalupe Rojas, M. and Shapiro-Ilan, D. (ed.) Mass production of beneficial organisms. Academic Press, San Diego, CA, USA, pp. 583-616. https://doi.org/10.1016/B9780-12-391453-8.00017-0

Garino, C., Mielke, H., Knüppel, S., Selhorst, T., Broll, H. and Braeuning, A., 2020. Quantitative allergenicity risk assessment of food products containing yellow mealworm (Tenebrio molitor). Food and Chemical Toxicology 142: 111460. https://doi.org/10.1016/j. fct.2020.111460

Gasco, L., Finke, M. and Van Huis, A., 2018. Can diets containing insects promote animal health? Journal of Insects as Food and Feed 4: 1-4. https://doi.org/10.3920/JIFF2018.x001
Gasco, L., Józefiak, A. and Henry, M., 2021. Beyond the protein concept: health aspects of using edible insects on animals. Journal of Insects as Food and Feed 7: 715-741. https://doi.org/10.3920/ JIFF2020.0077

Hartmann, C. and Siegrist, M., 2017. Consumer perception and behaviour regarding sustainable protein consumption: a systematic review. Trends in Food Science \& Technology 61: 11-25. https:// doi.org/10.1016/j.tifs.2016.12.006

The International Feed Industry Federation (IFIF), 2021. Global feed statistics. IFIF, Wiehl, Germany. Available at: https://ifif.org/globalfeed/statistics/

Joosten, L., Lecocq, A., Jensen, A.B., Haenen, O., Schmitt, E. and Eilenberg, J., 2020. Review of insect pathogen risks for the black soldier fly (Hermetia illucens) and guidelines for reliable production. Entomologia Experimentalis et Applicata 168: 432-447. https://doi. org/10.1111/eea.12916

Kaya, C., Generalovic, T.N., Ståhls, G., Hauser, M., Samayoa, A.C., Nunes-Silva, C.G., Roxburgh, H., Wohlfahrt, J., Ewusie, E.A., Kenis, M., Hanboonsong, Y., Orozco, J., Carrejo, N., Nakamura, S., Gasco, L., Rojo, S., Tanga, C.M., Meier, R., Rhode, C., Picard, C.J., Jiggins, C.D., Leiber, F., Tomberlin, J.K., Hasselmann, M., Blanckenhorn, W.U., Kapun, M. and Sandrock, C., 2021. Global population genetic structure and demographic trajectories of the black soldier fly, Hermetia illucens. BMC Biology 19: 94. https://doi.org/10.1186/ s12915-021-01029-w

Kok, R., 2017. Insect production and facility design. In: Van Huis, A. and Tomberlin, J.K. (eds.) Insects as food and feed: from production to consumption. Wageningen Academic Publishers, Wageningen, the Netherlands, pp. 143-172. https://doi.org/10.3920/978-908686-849-0

Kok, R., 2021a. Preliminary project design for insect production: part 1 - overall mass and energy/heat balances. Journal of Insects as Food and Feed 7: 499-509. https://doi.org/10.3920/JIFF2020.0055 Kok, R., 2021b. Preliminary project design for insect production: part 2 - organism kinetics, system dynamics and the role of modelling \& simulation. Journal of Insects as Food and Feed 7: 511-523. https:// doi.org/10.3920/JIFF2020.0146

Kok, R., 2021c. Preliminary project design for insect production: part 3 - sub-process types and reactors. Journal of Insects as Food and Feed 7: 525-539. https://doi.org/10.3920/JIFF2020.0145

Kok, R., 2021d. Preliminary project design for insect production: part 4 - facility considerations. Journal of Insects as Food and Feed 7:541-551. https://doi.org/10.3920/JIFF2020.0164

Lähteenmäki-Uutela, A., Marimuthu, S.B. and Meijer, N., 2021. Regulations on insects as food and feed: a global comparison. Journal of Insects as Food and Feed 7: 849-856. https://doi.org/10.3920/ JIFF2020.0066

Leip, A., Ledgard, S., Uwizeye, A., Palhares, J.C.P., Aller, M.F., Amon, B., Binder, M., Cordovil, C.M.d.S., De Camillis, C., Dong, H., Fusi, A., Helin, J., Hörtenhuber, S., Hristov, A.N., Koelsch, R., Liu, C., Masso, C., Nkongolo, N.V., Patra, A.K., Redding, M.R., Rufino, M.C., Sakrabani, R., Thoma, G., Vertès, F. and Wang, Y., 2019. The value of manure - manure as co-product in life cycle assessment. Journal of Environmental Management 241: 293-304. https://doi. org/10.1016/j.jenvman.2019.03.059 
Liland, N.S., Araujo, P., Xu, X.X., Lock, E.-J., Radhakrishnan, G., Prabhu, A.J.P. and Belghit, I., 2021. A meta-analysis on the nutritional value of insects in aquafeeds. Journal of Insects as Food and Feed 7: 743759. https://doi.org/10.3920/JIFF2020.0147

Maciel-Vergara, G., Jensen, A.B., Lecocq, A. and Eilenberg, J., 2021. Diseases in edible insect rearing systems. Journal of Insects as Food and Feed 7: 621-638. https://doi.org/10.3920/JIFF2021.0024 Mancini, S., Moruzzo, R., Riccioli, F. and Paci, G., 2019. European consumers' readiness to adopt insects as food. A review. Food Research International 122: 661-678. https://doi.org/10.1016/j. foodres.2019.01.041

Manyi-Loh, C., Mamphweli, S., Meyer, E. and Okoh, A., 2018. Antibiotic use in agriculture and its consequential resistance in environmental sources: potential public health implications. Molecules 23: 795. https://doi.org/10.3390/molecules23040795

Meticulous Research, 2021. Edible insects market to reach \$4.63 billion by 2027. Meticulous Research, Redding, CA, USA. Available at: https://www.meticulousresearch.com/pressrelease/184/edibleinsects-market-2027

Meyer, A.M., Meijer, N., Hoek-Van den Hil, E.F. and Van der Fels-Klerx, H.J., 2021. Chemical food safety hazards of insects reared for food and feed. Journal of Insects as Food and Feed 7: 823-831. https:// doi.org/10.3920/JIFF2020.0085

Motoki, K., Ishikawa, S.-I. and Park, J., 2021. Review and future directions of consumer acceptance of insect-based foods. The Japanese Journal of Psychology 92: 52-67. https://doi.org/10.4992/ jjpsy.92.204.02

Nardi, J.B., Mackie, R.I. and Dawson, J.O., 2002. Could microbial symbionts of arthropod guts contribute significantly to nitrogen fixation in terrestrial ecosystems? Journal of Insect Physiology 48: 751-763. https://doi.org/10.1016/S0022-1910(02)00105-1

Niyonsaba, H.H., Höhler, J., Kooistra, J., Van der Fels-Klerx, H.J. and Meuwissen, M.P.M., 2021. Profitability of insect farms. Journal of Insects as Food and Feed 7: 923-934. https://doi.org/10.3920/ JIFF2020.0087

Ojha, S., Bußler, S., Psarianos, M., Rossi, G. and Schlüter, O.K., 2021. Edible insect processing pathways and implementation of emerging technologies. Journal of Insects as Food and Feed 7: 877-900. https:// doi.org/10.3920/JIFF2020.0121

Oonincx, D.G.A.B. and Finke, M.D., 2021. Nutritional value of insects and ways to manipulate their composition. Journal of Insects as Food and Feed 7: 639-659. https://doi.org/10.3920/JIFF2020.0050

Oonincx, D.G.A.B., Van Keulen, P., Finke, M.D., Baines, F.M., Vermeulen, M. and Bosch, G., 2018. Evidence of vitamin D synthesis in insects exposed to UVb light. Scientific Reports 8: 10807. https:// doi.org/10.1038/s41598-018-29232-w

Peng, B.-Y., Su, Y., Chen, Z., Chen, J., Zhou, X., Benbow, M.E., Criddle, C., Wu, W.-M. and Zhang, Y., 2019. Biodegradation of polystyrene by dark (Tenebrio obscurus) and yellow (Tenebrio molitor) mealworms (Coleoptera: Tenebrionidae). Environmental Science \& Technology 53: 5256-5265. https://doi.org/10.1021/acs.est.8b06963

Pennisi, E., 2015. All in the (bigger) family. Revised arthropod tree marries crustacean and insect fields. Science of the Total Environment 347: 220-221. https://doi.org/10.1126/ science.347.6219.220
Pinotti, L., Luciano, A., Ottoboni, M., Manoni, M., Ferrari, L., Marchis, D. and Tretola, M., 2021. Recycling food leftovers in feed as opportunity to increase the sustainability of livestock production. Journal of Cleaner Production 294: 126290. https://doi.org/10.1016/j. jclepro.2021.126290

Pinotti, L. and Ottoboni, M., 2021. Substrate as insect feed for biomass production. Journal of Insects as Food and Feed 7: 585-596. https://doi.org/10.3920/JIFF2020.0110

Pittner, M., 2017. Consumer segment LOHAS. Nachhaltigkeitsorientierte Dialoggruppen im Lebensmitteleinzelhandel. Springer Fachmedien, Wiesbaden, Germany.

Ponce-Reyes, R. and Lessard, B., 2021. Edible insects - a roadmap for the strategic growth of an emerging Australian industry. Commonwealth Scientific and Industrial Research Organisation, Canberra, Australia. Available at: https://research.csiro.au/ edibleinsects/wp-content/uploads/sites/347/2021/04/CSIROEdible-Insect-Roadmap.pdf

Qi, X., Li, Z., Akami, M., Mansour, A. and Niu, C., 2019. Fermented crop straws by Trichoderma viride and Saccharomyces cerevisiae enhanced the bioconversion rate of Musca domestica (Diptera: Muscidae). Environmental Science and Pollution Research 26: 29388-29396. https://doi.org/10.1007/s11356-019-06101-1

Reverberi, M., 2021. The new packaged food products containing insects as an ingredient. Journal of Insects as Food and Feed 7: 901-908. https://doi.org/10.3920/JIFF2020.0111

Ribeiro, J.C., Sousa-Pinto, B., Fonseca, J., Fonseca, S.C. and Cunha, L.M., 2021. Edible insects and food safety: allergy. Journal of Insects as Food and Feed 7: 833-847. https://doi.org/10.3920/JIFF2020.0065

Riccaboni, A., Neri, E., Trovarelli, F. and Pulselli, R.M., 2021. Sustainability-oriented research and innovation in 'farm to fork' value chains. Current Opinion in Food Science 42: 102-112. https:// doi.org/10.1016/j.cofs.2021.04.006

Rozin, P., Haidt, J. and Fincher, K., 2009. Psychology. From oral to moral. Science 323: 1179-1180. https://doi.org/10.1126/science.1170492 Sindermann, D., Heidhues, J., Kirchner, S., Stadermann, N. and Kühl, A., 2021. Industrial processing technologies for insect larvae. Journal of Insects as Food and Feed 7: 857-875 https://doi.org/10.3920/ JIFF2020.0103

Smetana, S., Spykman, R. and Heinz, V., 2021. Environmental aspects of insect mass production. Journal of Insects as Food and Feed 7: 553-571. https://doi.org/10.3920/JIFF2020.0116

Sogari, G., Menozzi, D., Hartmann, C. and Mora, C., 2019. How to measure consumers acceptance towards edible insects? - a scoping review about methodological approaches. In: G. Sogari, C. Mora and D. Menozzi (eds.) Edible insects in the food sector: methods, current applications and perspectives. Springer International Publishing, Cambridge, UK, pp. 27-44. https://doi.org/10.1007/978-3-03022522-3_3

Stull, V.J., 2021. Impacts of insect consumption on human health. Journal of Insects as Food and Feed 7: 695-713. https://doi. org/10.3920/JIFF2020.0115

Van Boeckel, T.P., Brower, C., Gilbert, M., Grenfell, B.T., Levin, S.A., Robinson, T.P., Teillant, A. and Laxminarayan, R., 2015. Global trends in antimicrobial use in food animals. Proceedings of the National Academy of Sciences 112: 5649-5654. https://doi. org/10.1073/pnas.1503141112 
Van Huis, A., 2021. Welfare of farmed insects. Journal of Insects as Food and Feed 7: 573-584. https://doi.org/10.3920/JIFF2020.0061

Van Huis, A. and Tomberlin, J., 2017. Insects as food and feed: from production to consumption. Wageningen Academic Publishers, Wageningen, the Netherlands, 448 pp. https://doi.org/10.3920/97890-8686-849-0

Vandeweyer, D., De Smet, J., Van Looveren, N. and Van Campenhout, L., 2021. Biological contaminants in insects as food and feed. Journal of Insects as Food and Feed 7: 807-822. https://doi.org/10.3920/ JIFF2020.0060

Veldkamp, T. and Vernooij, A.G., 2021. Use of insect products in pig diets. Journal of Insects as Food and Feed 7: 781-793. https://doi. org/10.3920/JIFF2020.0091
Wassmann, B., Siegrist, M. and Hartmann, C., 2021. Correlates of the willingness to consume insects: a meta-analysis. Journal of Insects as Food and Feed 7: 909-922. https://doi.org/10.3920/JIFF2020.0130 Youssef, J. and Spence, C., 2021. Náttúra by kitchen theory: an immersive multisensory dining concept. International Journal of Gastronomy and Food Science 24: 100354. https://doi.org/10.1016/j. ijgfs.2021.100354

Zhang, J.B., Yu, Y.Q., Tomberlin, J.K., Cai, M.M., Zheng, L.Y. and Yu, Z.N., 2021. Organic side streams: using microbes to make substrates more fit for mass producing insects for use as feed. Journal of Insects as Food and Feed 7: 597-604. https://doi.org/10.3920/JIFF2020.0078 